\title{
A Case Report on Treatment Outcomes and Physiotherapy Rehabilitation of a Case with Smith's Fracture
}

\author{
Gunjan Shende', Ruchika Zade', Priyanka Sahu', Mitushi Deshmukh², \\ Shivani Bhurchandi², Pratik Phansopkar* \\ ${ }^{1}$ Department of Musculoskeletal Physiotherapy, Ravi Nair Physiotherapy College, \\ Datta Meghe Institute of Medical Sciences, Wardha, Maharashtra, India \\ ${ }^{2}$ Department of Musculoskeletal Physiotherapy, Ravi Nair Physiotherapy College, Datta \\ Meghe Institute of Medical Sciences, Wardha, Maharashtra, India. \\ Corresponding author email: drpratik77@gmail.com
}

\section{ABSTRACT}

Smith's fractures are the second most prevalent type of distal radius fractures but are much less common than Colle's fractures. The radius is the most often broken bone in the arm. But fractures in Smith's are still very unusual. They constitute fewer than $3 \%$ of all radius fractures.These are most commonly seen in young men and older women. Smith fracture signs are similar to those of other forms of fractures. Pain, tenderness, bruising and swelling are usually immediate. The wrist may bent or hang oddly in manner depending on the seriousness injury. A 40 years old right hand dominant female met with a road traffic accident. She visited physiotherapy clinic with complaints of stiffness and loss of strength in her left wrist while performing daily activities. Pain and swelling was present at wrist joint.Patient was hypertensive. X-rays revealed a palmar displacement of the wrist suggesting Smith's fracture. Patient was able to perform basic activities of daily living (ADLs). Her ability to lift objects was improved with the tasks which also involved supination/pronation were also improved.

KEY WORDS: RADIUS,SMITH'S FRACTURE, DISPLACEMENT, WRIST JOINT, REHABILITATION.

\section{INTRODUCTION}

Smith fracture is an eponym for an extraarticular distal radius fracture which has a volar displacement or distal fragment angulation. It's also called a reverse colles fracture, the distal fracture fragment dorsal displacement features as the colles fracture is more common. In 1847, Irish surgeon Robert William Smith named the Smith fracture, who incidentally followed Abraham Colles as professor of surgery at Trinity College in Dublin and performed and published Colles' autopsy. This injury was first named after the French doctor Jean-Gaspard-

Biosc Biotech Res Comm P-ISSN: 0974-6455 E-ISSN: 2321-4007

\section{rossef}

Identifiers and Pagination

Year: 2021 Vol: 14 No (6) Special Issue

Pages: 66-70

This is an open access article under Creative

DOI: $h t t p: / / d x$.doi.org/10.21786/bbrc/14.6.16
Commons License Attribn 4.0 Intl (CC-BY).
Blaise Goyrand (1746-1814), and is widely recognized as a Goyrand fracture in French literature (Schroede et al., 2020). Smith fractures are the second most prevalent type of distal radius fractures but are much less common than Colles fractures. The radius is the most often broken bone in the arm. But fractures in smiths are still very unusual. They constitute fewer than $3 \%$ of all radius fractures. These are most commonly seen in young men \&t older women.Smith fracture signs are similar to those of other forms of fractures. Pain, tenderness, bruising \& swelling are usually immediate. The wrist may bent or hang oddly in manner depending on the seriousness injury (Smith Fracture, 2017).

The fracture may be broken down into three types, Although a description in practice suffices -According to Frykman classification, the distal radial fractures are based on AP (antero-posterior) appearance and are divided into the following types explaining the pattern of fractures. Type 1-Extra-articular transverse fracture in

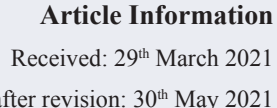

ccepted after revision: $30^{\text {th }}$ May 2021 
the distal radius is generally 85 per cent. Type 2-Intraarticular oblique fracture which is equivalent to a 13 percent reverse Barton fracture. Type 3-Juxtro-articular, which is rare i.e 2\% oblique fracture (Smith fracture, 2020). Functional independence measurement scale [FIM] found to be useful during rehabilitation (FIM, 2020). Functional Independence Measure (FIM) is a scale which is used to evaluate functional status during rehabilitation(Kay et al., 2000) .DASH scale [Disabilities of arm ,shoulder and hand] is found to be useful in this case report (Ginn et al., 2006; Hudak et al., 1996). This case report describes as a diagnosed case Smith fracture where distal fragment of radius is displaced volarly in a 40 years old female, right hand dominant and house wife by occupation, who met with an accident.

1. In previous studies, we can see the techniques given in management of smith fracture i.e Maitland mobilization and conventional mobilization which proved to be effective in reducing pain postintervention(Matsen et al., 1975). Paraffin wax bath for 15 minutes and exercise for 15 minutes (i.e wrist flexion, extension, ulnar and radial deviation and supination/pronation )also proved to be effective.

Patient Information: A 40 years old right hand dominant female met with a road traffic accident (housewife by occupation) visited physiotherapy clinic with her husband presenting the complaints of stiffness and loss of strength in her left wrist while performing daily activities. Patient was hypertensive. Her complaints were stiffness, pain and restricted movements in left wrist .She visited to a village where she found a herbal consultant who gave her conservative treatment by applying ayurvedic ointment on the fractured site. But she found no relief, so after 1 month (post herbal treatment) she visited to an orthopedic department. Medications were given at the orthopedic department, but she found no relief. Then she was advised for physiotherapy and was asked to do investigations. X-ray was done. The findings in X-ray showed displacement of distal part of radius.

Clinical Findings: A proper informed consent was taken from the patient prior. Physical examination was done .The patient was examined in sitting position with both shoulder at the same point. She was well oriented, conscious and cooperative to time, place, person, self and answerable to all the questions. X-ray showed slight displacement of distal part of radius. Swelling was present on left wrist. On palpation, diffuse tenderness was present at grade 2 and the wrist movements were restricted and local temperature was normal. Radioulnar joint stiffness and hard end-feel was present on examination. Garden-spade deformity could be seen in the X-ray. All neurological sensations were intact. Outcome measure NPRS (Numerical Pain Rating Scale) was 7.

RANGE of MOTION was evaluated of left hand which is shown in Table (before treatment and after treatment range was taken). Manual Muscle Testing (MMT) was evaluated in available ROM , which is shown in Table 2 (before treatment and after treatment grading was taken). DASH (Disabilities of Arm, Shoulder and Hand) score was also calculated before treatment and after treatment (Hudak et al., 1996).

\begin{tabular}{l} 
Table 1. Range of Motion \\
\hline Movement
\end{tabular}

Table 2. Manual Muscle Testing (Pre and Post rehabilitation grades)

\begin{tabular}{|l|c|c|}
\hline Muscles & Pre rehab Grade & Post rehab Grades \\
\hline Flexor & $4 / 5$ & $5 / 5$ \\
\hline Extensor & $3 / 5$ & $4 / 5$ \\
\hline Supinator & $3 / 5$ & $4 / 5$ \\
\hline Pronator & $4 / 5$ & $5 / 5$ \\
\hline
\end{tabular}

PRE and POST Rehabilitation Ranges:

Pain Assessment:
Pre-rehab NPRS: 7/10 at rest , 8/10 on slight movement.

Post-rehab NPRS: 2/10 at rest , 4/10 on slight movement.

Disabilities of Arm, Shoulder and Hand (DASH) score:

Pre-rehab score : 65

Post-rehab score : 20

Intervention:

Medications were given

Description: Smith fracture recovery focuses on pain 
control and helps the patient to recover balance, improve strength and most importantly return to work (2). Patient education, cryotherapy, electrotherapy modalities, thermotherapy, range of motion exercises, progressive resistant exercises and joint mobilization techniques were included.

Figure 1: X-ray showing: Initial roentgenograms of the left wrist showing volar displacement of the distal radius , showing the characteristics of smith fracture.
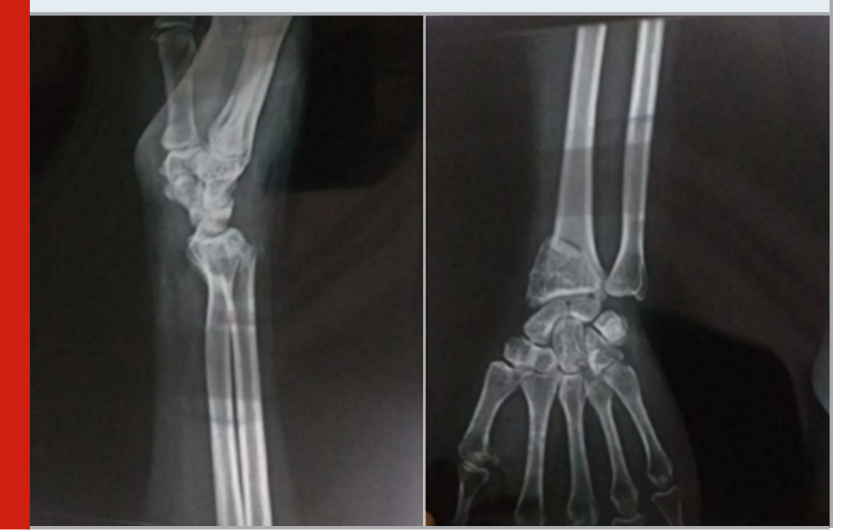

\section{WEEK 1}

Cryotherapy: Application of an ice pack for 5-10 mins of duration, to reduce swelling over the joint and to prevent muscle soreness. Paraffin wax bath in form of pouring method was given. It helps relax the muscles, improve local circulation and reduce pain and spasm (Murray et al., 2019). Ultrasound given on continuous mode with frequency of $1 \mathrm{MHz}$ by using the direct contact method for 8 minutes duration. It helps to reduce pain and has placebo effect. Range of motion exercises within pain free limit were started. Active assisted exercise were given

\section{WEEK 2}

Paraffin wax bath, Ultra sound and range of motion exercises were continued. Wrist mobilization (in form of dorsal and volar glides and with grade III and grade IV) was initiated with a small range of relaxed speedy flexion-extension with forearm in mid-prone position (Kay et al., 2000). It improves range of motion. A proximal radioulnar volar glide was also given to increase supination. Patient was in supine position with elbow flexed in 700 and with forearm supinated in 350. Forcing the radial head volarly by pushing with therapist's palm or pulling with fingers. Gripping exercises were also started. It includes cylindrical, spherical, hook grip and lateral prehension.

\section{Range of motion exercises}

Self assisted passive stretching: It was performed with palm of the patient over the edge of the table and self assisted wrist flexion and extension was performed. Wand or good hand can be used for improving the pronation and supination, passive ROM exercises for shoulder and elbow. It helps to prevent contractures and deformities. 10 repetitions were given for 2 times a day.

\section{WEEK 3}

The previous treatment was continued and exercise was modified with resistance such as, Self resistive or with the help of weight cuff (initiated with $1 / 2 \mathrm{~kg}$ ). The ROM exercise was started for increasing the strength. Self resistive exercise was progressed with increased weight i.e from $1 / 2 \mathrm{~kg}$ to $1 \mathrm{~kg}$ and then $2 \mathrm{~kg}$. Home exercise program was also explained and advised. Ergonomic was also given.

Figure 2: Before treatment:- Extension of wrist and supination of forearm.

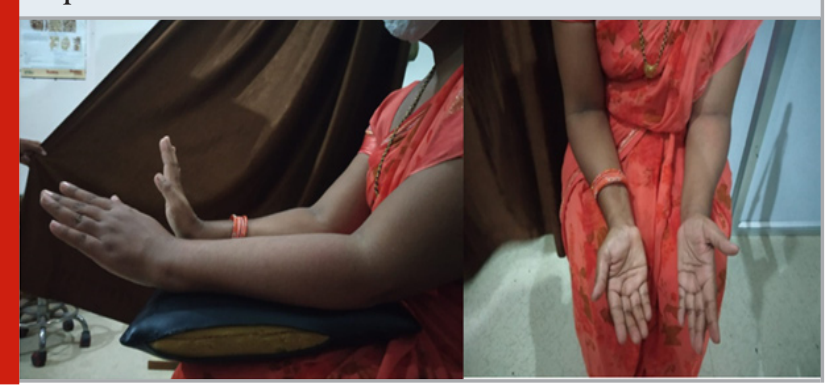

Figure 3: After treatment:- Extension of wrist and supination of forearm.

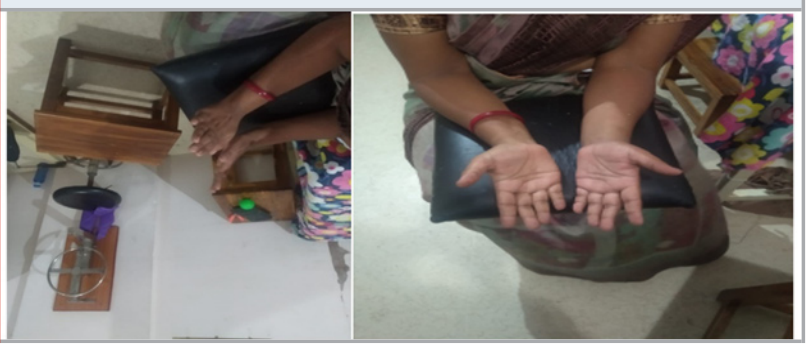

Follow-up and Outcome: Post 3 weeks of rehabilitation, patient showed remarkable improvements as shown above in Table 1 and Table 2.

\section{RESULTS}

The range of motion was improved. Swelling and pain during movements reduced. Patient was able to do the household activities.

\section{DISCUSSION}

The important feature of this injury is, fracture of the radius bone just above wrist, with the distal fragment and carpus volarly displaced, the mechanism by which a Smith fracture is sustained. While evaluating, it can be figured out that it is important to use a combination of recorded symptoms (i.e. pain and function), ROM and functional ability in the outcome measures to be used in this study.

The Paraffin Wax Bath and Ultrasound began at the first day of session helped to reduce the swelling and at the second session wrist mobilization and proximal radioulnar volar glide was given which helped to increase supination (Ginn et al., 2006). After mobilization, 
cryotherapy was given to prevent muscle soreness and self-assisted passive stretching which began at the second session of physiotherapy .Cryotherapy relieved local pain and swelling. Pain and all measures of ROM and functions improved dramatically over the distal part of radius and were handled with a passive course of mobilization, with advice and exercises. As patient had not undergone any surgery, attempts have been made to determine patient's compliance with exercise at home. The physiotherapist reviewed the exercises at follow-up consultations to ensure that they were properly performed. With passive mobilization ,ROM and DASH scale score was conceived solely for use in the study, as it was not specific to existing scales enough for wrist joint functioning.

Each of the wrist joint complex's ROM outcomes and the grip force over time, showed considerable change. Extension and supination were also found to be in full ROM. Functional task performances were also significantly improved over time. As the patient was housewife, to recover sooner was very essential for her so the treatment session was largely focused on mobilization

Patient had previously reported frequent difficulties, such as lifting the objects, weight bearing occurring through the extended wrist \& tasks involving supination or pronation. While the DASH scale conceived and applied in this study seemed sensitive to be changed, it was quick to admit and showed reasonable reliability intrarater and relative experience being a conclusive test of wrist function (Hudak et al., 1996). Similar articles are reported in GBD studies (James et al., 2020a; James et al., 2020b; Murray et al., 2020; Murray et al., 2019; Vos et al., 2019). Studies on different types of fracture were also reported by Dhankar and Bele (2019), Reddy and Dhaniwala (2019).. Few related studies were reviewed (Dongre et al., 2019; Gaidhane et al., 2018; Mundada et al., 2017).Related studies by Bawiskar et al. (2020), Phansopkar et al. (2020), Reddy et. al. (2020) and Saoji et al. (2020) were reported.

\section{CONCLUSION}

The above case report concludes prompt structured physiotherapy rehabilitation led to improving the functional goals progressively which is a major aspect in leading to a successful recovery in such patients. In this case report, it is found that passive mobilization of the wrist helped in patient recovery, thus demonstrating it's effectiveness. Patient is able to perform basic activities of daily living. Her ability to lift objects improved with the tasks which involved supination/pronation. Passive ROM exercises prevented forming contractures and deformity. Whereas self -resistive exercises using weight cuff had an impact on increasing strength.

\section{List of Abbreviation}

ROM - Range Of Motion

MMT- Manual Muscle Testing
Authors contribution: All authors made best contribution for the concept, evaluation and assessment, interpretation of the data analysis and data acquisition.

\section{Conflict of interest: None}

\section{Funding support: None}

Patient consent: Proper consent was taken from patient for writing case report.

\section{REFERENCES}

Bawiskar, D.P., Bais, A.S., Naqvi, W.M. and Sahu, A., 2020. Physiotherapy Approach towards a Typical Case of Injection Induced Radial Nerve Palsy Presenting as Wrist Drop. Journal of Evolution of Medical and Dental Sciences, 9(22), pp.1722-1725.

Dhankar, S. and Bele, A., 2019. A case of fracture shaft femur in a patient with transtibial amputation. Journal of Datta Meghe Institute of Medical Sciences University, 14(4), p.394.

Dongre, P., Chandak, A.V., Singam, A. and Bapat, A.V., Evaluation of Low Dose Dexmedetomidine and Neostigmine with Bupivacaine for Post-Operative Epidural Analgesia in Lower Limb Orthopedic Surgeries. International Journal of Pharmaceutical Research, 11, pp.1874-77.

Functional Independence Measure (FIM) [Internet]. Physiopedia. [cited 2020 Nov 28]. Available from: https:// www.physio-pedia.com/Functional_Independence_ Measure_(FIM)

Gaidhane, A.M., Sinha, A., Khatib, M.N., Simkhada, P., Behere, P.B., Saxena, D., Unnikrishnan, B., Khatib, M., Ahmed, M. and Syed, Z.Q., 2018. A systematic review on effect of electronic media on diet, exercise, and sexual activity among adolescents. Indian journal of community medicine: official publication of Indian Association of Preventive \& Social Medicine, 43(Suppl 1), p.S56.

Ginn, T.A., Ruch, D.S., Yang, C.C. and Hanel, D.P., 2006. Use of a distraction plate for distal radial fractures with metaphyseal and diaphyseal comminution. JBJS, 88(1_suppl_1), pp.29-36.

Hudak, P.L., Amadio, P.C., Bombardier, C. 1996. Development of an upper extremity outcome measure: the DASH (disabilities of the arm, shoulder and hand) [corrected]. The Upper Extremity Collaborative Group (UECG). Am J Ind Med., (6), pp.602-8.

James, S.L., Castle, C.D., Dingels, Z.V., Fox, J.T., Hamilton, E.B., Liu, Z., Roberts, N.L., Sylte, D.O., Bertolacci, G.J., Cunningham, M. and Henry, N.J., 2020. Estimating global injuries morbidity and mortality: methods and data used in the Global Burden of Disease 2017 study. Injury Prevention, 26(Supp 1), pp.i125-i153.

Kay, S., Haensel, N., Stiller, K. 2000. The effect of passive mobilisation following fractures involving the distal radius: a randomised study. Australian Journal of Physiotherapy. 46(2), pp.93-101. 
Latchoumi, T.P., Ezhilarasi, T.P. and Balamurugan, K., 2019. Bio-inspired weighed quantum particle swarm optimization and smooth support vector machine ensembles for identification of abnormalities in medical data. SN Applied Sciences, 1(10), pp.1-10.

Matsen 3rd, F.A., Questad, K. and Matsen, A.L., 1975. The effect of local cooling on postfracture swelling. A controlled study. Clinical orthopaedics and related research, (109), pp.201-206.

Mundada, G., Khan, S.M., Singhania, S.K., Gupta, V., Singh, P.K. and Khan, S., 2017. Type-I monteggia with ipsilateral fracture of distal radius epiphyseal injury: A rare case report. Annals of African medicine, 16(1), p.30.

Murray, C.J., Abbafati, C., Abbas, K.M., Abbasi, M., Abbasi-Kangevari, M., Abd-Allah, F., Abdollahi, M., Abedi, P., Abedi, A., Abolhassani, H. and Aboyans, V., 2020. Five insights from the global burden of disease study 2019. The Lancet, 396(10258), pp.1135-1159. Murray, C.J., Aravkin, A.Y., Zheng, P., Abbafati, C., Abbas, K.M., Abbasi-Kangevari, M., Abd-Allah, F., Abdelalim, A., Abdollahi, M., Abdollahpour, I. and Abegaz, K.H., 2020. Global burden of 87 risk factors in 204 countries and territories, 1990-2019: a systematic analysis for the Global Burden of Disease Study 2019. The Lancet, 396(10258), pp.1223-1249.

Phansopkar, P., Athawale, V., Birelliwar, A., Naqvi, W. and Kamble, S., 2020. Post-operative rehabilitation in a traumatic rare radial nerve palsy managed with tendon transfers: a case report. The Pan African Medical Journal, 36.

Reddy, S. and Dhaniwala, N., 2019. Diaphyseal fractures in pediatric age group in rural area: A demographic study. Journal of Datta Meghe Institute of Medical Sciences University, 14(3), p.189.

Reddy, S.M. and Dhaniwala, N.S., 2020. Outcome of Surgically Managed Diaphyseal Fractures in Children-A Prospective Study. JOURNAL OF EVOLUTION OF MEDICAL AND DENTAL SCIENCES-JEMDS, 9, pp.39397.

Saoji, K., Mohit, D., Gajanan P., Aditya, K., Amit, S. Infected Non Union in an Operated Compound Fracture of Shaft of Humerus: A Case Report. MEDICAL SCIENCE, 24(105) pp.3215-21.

Schroeder, J.D., Varacallo, M. 2020. Smith's Fracture Review [Internet]. StatPearls [Internet]. StatPearls Publishing; Available from: https://www.ncbi.nlm.nih. gov/books/NBK547714/

Smith fracture | Radiology Case | Radiopaedia.org [Internet]. [cited 2020 Nov 28]. Available from: https:// radiopaedia.org/cases/smith-fracture?lang=us

Smith Fracture: Healing Time, Treatment, Symptoms, and More [Internet]. Healthline. 2017 [cited 2020 Nov 28]. Available from: https://www.healthline.com/health/ smith-fracture

Spencer L, Chris D, Zachary V, Jack T, Erin B, Zichen L, Nicholas L, Roberts S, Dillon 0, Nathaniel J, Kate E. Global injury morbidity and mortality from 1990 to 2017: results from the Global Burden of Disease Study 2017.

Vos, T., Lim, S.S., Abbafati, C., Abbas, K.M., Abbasi, M., Abbasifard, M., Abbasi-Kangevari, M., Abbastabar, H., Abd-Allah, F., Abdelalim, A. and Abdollahi, M., 2020. Global burden of 369 diseases and injuries in 204 countries and territories, 1990-2019: a systematic analysis for the Global Burden of Disease Study 2019. The Lancet, 396(10258), pp.1204-1222. 